\title{
The performance of a modified EWMA control chart for monitoring autocorrelated PM2.5 and carbon monoxide air pollution data
}

\author{
Yadpirun Supharakonsakun $^{1}$, Yupaporn Areepong ${ }^{\text {Corresp., } 1}{ }^{\text {, Saowanit Sukparungsee }}{ }^{1}$ \\ ${ }^{1}$ Department of Applied Statistics, King Mongkut's University of Technology North Bangkok, Bangkok, Bangkok, Thailand \\ Corresponding Author: Yupaporn Areepong \\ Email address: yupaporn.a@sci.kmutnb.ac.th
}

PM2.5 (particulate matter less than or equal to 2.5 micron) is found in the air and comprises dust, dirt, soot, smoke, and liquid droplets. PM2.5 and carbon monoxide emissions can have a negative impact on humans and animals throughout the world. In this paper, we present the performance of a modified exponentially weighted moving average (modified EWMA) control chart to detect small changes when the observations are autocorrelated with exponential white noise through the average run length evaluated (ARLs) by explicit formulas. The accuracy of the solution was verified with a numerical integral equation method. The efficacy of the modified EWMA control chart to monitor PM2.5 and carbon monoxide air pollution data and compare its performance with the standard EWMA control chart. The results suggest that the modified EWMA control chart is far superior to the standard one. 
1 The Performance of a Modified EWMA Control Chart for

2 Monitoring Autocorrelated PM2.5 and Carbon Monoxide

3 Air Pollution Data

4

Yadpirun Supharakonsakun ${ }^{1}$, Yupaporn Areepong ${ }^{2}$, Saowanit Sukparungsee ${ }^{3}$

1,2,3 Department of Applied Statistics, King Mongkut's University of Technology North

8 Bangkok, Thailand, Bangkok, Thailand

Corresponding Author:

Yupaporn Areepong ${ }^{2}$

1518 Pracharat 1 Road, Wongsawang, Bangsue, Bangkok, 10800, Thailand

Email address: yupaporn.a@sci.kmutnb.ac.th

\section{Abstract}

PM2.5 (particulate matter less than or equal to 2.5 micron) is found in the air and comprises dust, dirt, soot, smoke, and liquid droplets. PM2.5 and carbon monoxide emissions can have a negative impact on humans and animals throughout the world. In this paper, we present the performance of a modified exponentially weighted moving average (modified EWMA) control chart to detect small changes when the observations are autocorrelated with exponential white noise through the average run length evaluated (ARLs) by explicit formulas. The accuracy of the solution was verified with a numerical integral equation method. The efficacy of the modified EWMA control chart to monitor PM2.5 and carbon monoxide air pollution data and compare its performance with the standard EWMA control chart. The results suggest that the modified EWMA control chart is far superior to the standard one.

\section{Introduction}

One of the world's greatest health and environmental problems is air pollution, which has steadily increased worldwide due to global industrialization and urbanization (Manisalidis et al., 2020). Air quality monitoring in many countries has shown that the levels of common pollutants have increased from 1980 until now. During 2010-2016, an estimated 55.3\% of the global population were exposed to dangerous levels of air pollution (Shaddick et al., 2020). Therefore, a major global health risk to the world's population is air pollution, with more than $90 \%$ of people living in areas that do not meet the 2017 World Health Organization's (WHO) recommended threshold of air quality levels (Health Effects Institute, 2019). The WHO data also reveals that in 2016, 6.1 million deaths worldwide (around 11\% of the total global deaths) are attributable to air pollution.

A widespread air pollutant consisting of a mixture of solid and liquid particles suspended in air is called particulate matter (PM), in which the physical and chemical characteristics depend on the location. The common chemical components of PM include nitrates, sulfates, ammonium, other inorganic, and biological compounds (Hung et al., 2014). PM is used as an indicator that is 
41

42

43

44

45

46

47

48

49

50

51

52

53

54

55

56

57

58

59

60

61

62

63

64

65

66

67

68

69

70

71

72

73

74

75

76

77

78

79

80

81

82

83

84

relevant to health and is classified in terms of the diameter or width of the particles, e.g. PM10 means the diameter is $10 \mu \mathrm{m}$ or less and PM2.5 is $2.5 \mu \mathrm{m}$ or less (Saarikoski et al., 2018). PM2.5 can be human-made and naturally occurring. Air pollution from vehicle emissions and traffic congestion produces both PM2.5 and carbon monoxide (CO) pollution, with major causes being diesel engine exhaust fumes and traffic congestion (Pui et al., 2014; Tian et al., 2015). Emissions from factories and power plants are also major causes of PM2.5 pollution due to burning fossil fuels, especially coal (Hua et al., 2015). Moreover, the burning of agricultural waste, especially in South East Asia, and forest fires are other major causes of PM2.5 pollution (He et al., 2020; Lee et al., 2018).

The small size of PM2.5 particles makes them particularly deleterious to health by directly cause respiratory and cardiovascular morbidity. Since the lungs are the primary organs affected by PM2.5, exposure can lead to lung injury by perturbations of the lung microbiome and its associated metabolome mechanism (Li et al., 2020), as well as causing respiratory diseases and lung cancer (Xing et al., 2015). However, PM2.5-induced neuroinflammation and metabolic turbulence may be mitigated by the anti-inflammatory and anti-oxidative activities of fisetin (Xu et al., 2020). Long-term exposure to PM pollution in the air causes extrinsic skin aging, (wrinkles and changes in pigmentation). Moreover, atmospheric pollutants also lead to skin diseases such as atopic dermatitis (Liao et al., 2020).

The trend in Central and Southern Asia has been a rise in PM2.5 levels between 2010 and 2016 (Shaddick et al., 2020; Cheong et al., 2019; Johnston et al., 2019). Recently in Thailand, especially in Bangkok and the surrounding area, the population has been exposed to dangerously high PM2.5 pollution levels due to agricultural waste burning, foreign sources, and industry. The levels of these small particles have increased over the past few years (Wimolwattanapun et al., 2011; Oanh et al., 2013; Pinichka et al., 2017; Mahidol University, 2020). Self-care practices should be the first priority to manage this problem, while PM2.5 pollution levels should be kept under control and closely monitored periodically.

Statistical process control is a quality control approach for carrying out statistical methods to monitor and control process change. Especially, the control chart is a tool that is widely used to monitor processes to detect any changes in them, thereby preventing the occurrence of faults. In many ecological and environmental sources of data, the values are not independent over time and often comprise autocorrelated observations (autocorrelation or serial correlation is a measure of the correlation between current variable values and their past ones). Hence, the assumption in traditional control chart methodology that the observations taken from the process are independent and normally distributed does not hold. Thus, traditional control charts such as the Shewhart control chart have drastically reduced efficiency when applied to serially correlated observations. Therefore, many researchers have proposed the cumulative sum (CUSUM) (Page, 1954) and exponentially weighted moving average (EWMA) (Roberts, 1959) control charts as suitable alternatives for when the observations are autocorrelated. The EWMA control chart is recommended when the observations are not normally distributed or are autocorrelated, as has been determined using the average run length (ARL) statistic (Srivasrava,1993; Wardell et al., 1994; Jiang et al., 2000; Carson \& Yeh, 2008; Han et al., 2010). The usefulness of control chart techniques has been investigated for air pollution data in a time series. The CUSUM control chart has been employed for identifying changes in the mean air pollution level (Barratt et al. 2006), as well as for identifying important change-points in the time series of air pollutants

Peer] reviewing PDF | (2020:07:50582:5:0:NEW 4 Nov 2020) 
85

86

87

88

89

90

91

92

93

94

95

96

97

98

99

100

101

102

103

104

105

106

107

108

109

110

111

measured at a busy roadside location in central London (Carslaw et al. 2006). The applicability of the CUSUM control chart for detecting changes in air pollutant concentrations in Delhi was investigated by Chelani (2011), who found that they have been significantly increasing over time. Moreover, standard CUSUM and EWMA control charts have been used to detect a change in air pollutant time series data in Kuwait (Al-Rashed et al. 2019); the results reveal that both procedures provided early alarms in the detection of changes in air pollutants. Afterward, a newly structure control statistic was proposed by Patel and Devecha (2011) and was also generalized structure of control statistic namely modified EWMA control chart. Several researchers investigated the performance of modified EWMA chart by different situations of non-normal distribution including Aslam et al. (2017), Herdiani et al. (2018), Noiplab and Mayureesawan (2019). The application of modified EWMA procedures were demonstrated using real-life samples by comparing with the existing charts. The results showed that the proposed control chart is efficient in quick detection of the out-of-control process (Khan et al.,2018; Saghir et al., 2019; Saghir et al., 2020; Aslam and Anwar, 2020; Supharakonsakun et al., 2020).

According to these prior studies on control chart performance, the ARL is utilized to measure the robustness of the chart. In this paper, a modified EWMA control chart, which was newly developed from the traditional EWMA procedure, is presented for monitoring and detecting small and abrupt changes in autocorrelated data by evaluating the ARL. Its performance was studied comparatively with the standard EWMA chart for detecting changes in PM2.5 and CO gas level.

\section{Modified EWMA Chart}

Robert (1959) first proposed the EWMA control chart that is very effectively at detecting small process changes. This chart's design parameters are the multiples of widths of the control limit and smoothing parameter. The EWMA statistic is defined as

$$
Z_{t}=(1-\lambda) Z_{t-1}+\lambda X_{t}
$$

where $0<\lambda \leq 1$ is smoothing parameter and $X_{t}, t=1,2,3, \ldots$ is a sequence of autocorrelated observations with the starting value is the process target mean $Z_{0}=\mu_{0}$.

The respective upper and lower control limits for the EWMA chart are

$$
\begin{aligned}
& U C L=\mu_{0}+H \sigma \sqrt{\frac{\lambda}{2-\lambda}\left[1-(1-\lambda)^{2 i}\right]}, \\
& L C L=\mu_{0}-H \sigma \sqrt{\frac{\lambda}{2-\lambda}\left[1-(1-\lambda)^{2 i}\right]},
\end{aligned}
$$

112 where $H$ is the width of the control limit and $\sigma$ is the process standard deviation. The term

$113\left[1-(1-\lambda)^{2 i}\right]$ is close to 1 as $i$ becomes large. Hence, the respective upper and lower control

114 limit will approach their respective steady-state value as 


$$
U C L=\mu_{0}+H \sigma \sqrt{\frac{\lambda}{2-\lambda}}
$$

115 and

$$
L C L=\mu_{0}-H \sigma \sqrt{\frac{\lambda}{2-\lambda}},
$$

116

117

118

119

120

121

122

123

124

125

126

127

128

129

130

131

132

133

134

135

136

137

Later, modified EWMA control chart was introduced by Patel and Divecha (2011). They corrected the inertia problem caused by errors in the EWMA statistic by considering past changes as well as the latest change in the process. The modified EWMA chart is useful for detecting process changes in observations that are autocorrelated or independent normally distributed. Recently, Khan et al. (2017) proposed a new control statistic structure that developed from the modified EWMA control chart as follow:

$$
Z_{t}=(1-\lambda) Z_{t-1}+\lambda X_{t}+k\left(X_{t}-X_{t-1}\right),
$$

where $\lambda$ is the smoothing parameter; $X_{t}, t=1,2,3, \ldots$ is a sequence of autocorrelated observations; $k$ is a constant; and the starting value is the process target mean $Z_{0}=\mu_{0}$. It is similar to the EWMA statistic but with the last term extended.

This chart generates a false alarm when the $Z_{n}$ value violates the specified control limit. In general, the upper and lower control limit are respectively given by

$$
U C L=\mu_{0}+L \sigma \sqrt{\frac{\lambda+2 k \lambda+2 k^{2}}{2-\lambda}},
$$

and

$$
L C L=\mu_{0}-L \sigma \sqrt{\frac{\lambda+2 k \lambda+2 k^{2}}{2-\lambda}},
$$

where $L$ and $\sigma$ is the width of the control limit of modified EWMA procedure and process standard deviation, respectively.

\section{Method of Evaluating ARL for Moving Average Order q Model}

A time series is a series of data points ordered in time, and the goal of a time series analysis is usually to make a forecast of the future using time as an independent variable. A usual characteristic of a time series is autocorrelation, which is correlation between observations in the same dataset at different points in time. In other words, autocorrelated data portrays the similarity between observations as a function of the time lag between them. In a time series analysis, an MA(q) process is a common approach for modeling a univariate time series for which the error depends linearly on the current and numerous past values of the error term.

$$
X_{t}=\mu+\varepsilon_{t}-\theta_{1} \varepsilon_{t-1}-\theta_{2} \varepsilon_{t-2}-\ldots-\theta_{q} \varepsilon_{t-q},
$$


138

140

141

142

143

where $\mu$ is the mean of the series, $\varepsilon_{t}$ is a white noise process assumed to be exponentially distributed, $\theta_{i}$ is a process coefficient, and the starting value of $\varepsilon_{0}=s$ is given.

Let $L(u)$ denote the ARL for an MA(q) process with exponential white noise on a modified EWMA control chart (see Appendix A1 for the proof) that there exists only one solution of the integral equation (see Appendix A2). It is obtained by deriving a Fredholm integral equation of the second kind as follows:

$$
L(u)=1-\frac{\lambda e^{\frac{(1-\lambda) u}{\alpha_{0}(\lambda+k)}}\left[e^{-\frac{b}{\alpha_{0}(\lambda+k)}}-1\right]}{\lambda e^{\frac{-\mu}{\alpha_{0}}} \cdot e^{\frac{v+\left(\lambda \theta_{1}+\theta_{1} k\right) s+\left(\lambda \theta_{2}+\theta_{2} k\right) \varepsilon_{t-2}+\ldots+\left(\lambda \theta_{q}+\theta_{q} k\right) \varepsilon_{t-q}}{\alpha_{0}(\lambda+k)}}+e^{-\frac{\lambda b}{\alpha_{0}(\lambda+k)}}-1},
$$

144

145

146

147

148

149

150

151

152

153

154

155

156

157

158

159

160

161

162

163

164

165

166

with in-control process parameter $\alpha_{0}$ and out-of-control process parameter $\alpha_{1}>\alpha_{0}$.

\section{Numerical Results}

The ARLs of the explicit formulas are derived using a Fredholm integral equation of the second type, those of the numerical integral equation method are approximated using the GaussLegendre quadrature rule with 1,000 nodes, and the control ARL is set to $\mathrm{ARL}_{0}=500$. The numerical approximation of the numerical integral equation and the exact result of the explicit formulas to measure the accuracy in the comparative study according to the relative error is defined as

$$
\varepsilon=\frac{|L(u)-\hat{L}(u)|}{L(u)} \times 100 \%,
$$

where $L(u)$ is derived from the ARL using the explicit formulas and $\hat{L}(u)$ is an approximation of the ARL with the numerical integral equation. The numerical results are reported in Tables 1 3.

Computation of the ARL by using the explicit formulas and the numerical integral equation method on the modified EWMA control chart were carried out with a varied smoothing parameters $(\lambda=0.05,0.10,0.15$ and 0.2$)$; constant $k=1$; in-control process parameter $\alpha_{0}=1$; out-of-control process parameter $\alpha_{1}=(1+\delta) \alpha_{0}$, where $\delta$ is the shift size set as $0.001,0.003$, $0.005,0.01,0.05,0.10,0.50$ or 1.00; and in-control process was $\mathrm{ARL}_{0}=500$ (Tables 1 and 2). The parameters were set as $\mu=2$; coefficients $\theta_{1}=-0.3, \theta_{2}=0.5$ with $\lambda=0.05,0.1$ and $\theta_{1}=0.1, \theta_{2}=0.3$ with $\lambda=0.15,0.2$ for an $\mathrm{MA}(2)$ process; and coefficients $\theta_{1}=0.3, \theta_{2}=0.5$, $\theta_{3}=0.7$ with $\lambda=0.05,0.1$ and $\theta_{1}=-0.5, \theta_{2}=-0.3, \theta_{3}=-0.5$ with $\lambda=0.15,0.2$ for an $\operatorname{MA}(3)$ process. The results indicate that when the smoothing parameter was increased, the value of $\mathrm{ARL}_{1}$ was reduced.

The results in Tables 1 and 2 show that the analytically explicit expression of the ARL was in excellent agreement with the approximated ARL obtained from the numerical integral 
167

168

169

170

171

172

173

174

175

176

177

178

179

180

181

182

183

184

185

186

187

188

189

190

191

192

193

194

195

196

197

198

199

200

201

202

equation (NIE) method. The computational time for the numerical integral equation method was around 21 and 23 seconds for the MA(2) and MA(3) processes, respectively, while the explicit formulas required a computational time of less than one second for both.

Table 3 reports the ARL values obtained by using the explicit formulas and numerical integral equation method. The parameters were set as $\mu=2$; coefficient parameters $\theta_{1}=-0.3$, $\theta_{2}=0.7, \theta_{3}=-0.5$ for $\mathrm{MA}(3)$ process; $\lambda=0.1$; and $k$ was varies as $5 \lambda, 10 \lambda, 20 \lambda$, or $50 \lambda$. The results revealed that when the constant $k$ was large, $\mathrm{ARL}_{1}$ was reduced.

The performances of the standard and modified EWMA control charts were also compared. These were obtained by the explicit expression when varying $\lambda(0.05$ and 0.10$)$ for both control charts, as reported in Tables 4 and 5. The observations were from the $\operatorname{MA}(2)$ and $\operatorname{MA}(3)$ processes with $\theta_{1}=-0.1, \theta_{2}=-0.3$, and $\theta_{1}=0.7, \theta_{2}=0.7, \theta_{3}=-0.1$, respectively, for $\mu=2$, $k=1$, and $\mathrm{ARL}_{0}=500$. The last row is the relative mean index $(R M I)$ defined as

$$
R M I=\frac{1}{n} \sum_{i=1}^{n}\left[\frac{A R L_{\delta_{i}}-A R L_{\delta_{i}}^{\text {smallest }}}{A R L_{\delta_{i}}^{\text {smallest }}}\right],
$$

where $A R L_{\delta_{i}}$ denotes the ARLs of the EWMA and modified EWMA control charts obtained via the explicit formulas for each shift size and $A R L_{\delta_{i}}^{\text {smallest }}$ denotes the smallest of the ARLs for each shift size.

The results in Table 4 show that when $\lambda=0.05$, the performance of the modified EWMA control chart was better than the standard one for shift sizes of $0.001,0.003,0.005,0.01,0.05$, 0.10 and 0.30 , whereas for shift size of $0.50,1.00$, and 2.00 , the small $R M I$ of the modified EWMA chart was 0.057529 while that the RMI of the EWMA control chart was 3.266348 . When $\lambda=0.1,0.15$ and 0.2 , the modified EWMA control chart was more powerful than the standard one for all cases of shift size with the zero RMI. The results indicate that overall, the modified EWMA control chart was better than the standard one at detecting process changes.

\section{Application of the modified EWMA Chart}

PM2.5 and CO gas air pollutants are being constantly emitted, which is likely to increase over time in the winter and summer seasons. When the levels of these air pollutants are high ( $>50$ $\mu \mathrm{g} / \mathrm{m}^{3}$ for PM2.5 (https://en.wikipedia.org/wiki/Air_quality_guideline) and > 10000 ppm for CO (https://www.airqualitynow.eu/download/CITEAIR-Comparing_Urban_Air_Quality_across_Bor ders.pdf), the quality of the ambient air is unhealthy to humans. Increasing PM2.5 concentration can lead to coughing, breathing difficulties, and eye irritation and can be deadly to humans.

Table 5 contains a comparison of the ARLs of the modified and standard EWMA control charts obtained via the explicit formulas. PM2.5 and CO measurements were taken every day in January and May, respectively, 2020 by the Pollution Control Department, Thailand. There were small and abrupt changes in the PM2.5 and CO level data in the Din Daeng district of Bangkok (where there is a high volume of traffic) from measurements near a busy road (Chuersuwan et al., 2008). The PM2.5 and CO air pollution level data were tested for autocorrelation in the 
203

204

205

206

207

208

209

210

211

212

213

214

215

216

217

218

219

220

221

222

223

224

225

226

227

228

229

230

231

232

233

234

235

236

237

238

239

240

241

242

observations. The Box-Jenkins technique was applied to the two air pollution datasets to determine whether they fit forecast time series data models. The models with the lowest Akaike Information Criterion (AIC) and Bayesian Information Criterion (BIC) values were considered as optimal. Moreover, t-test statistics proved that the two datasets were autocorrelated. The parameter values for the MA(1) and MA(2) processes were fitted and provided 51.163 for the mean and -0.723 and -0.380 for the coefficients, respectively. The PM2.5 level was found to be significant for the MA(2) process.

The efficiency of the modified EWMA procedure was also emphasized by its performance with the CO level data for the Din Daeng district, Bangkok, Thailand. Table 6 displays the ARLs of the modified and traditional EWMA control charts. The explicit formulas were used for measuring the ARLs of the CO gas level. The data were collected every day in May 2020. The analysis for an MA autocorrelated process resulted in a mean of 1.198 and $-0.662,-0.479$, and 0.495 for the coefficients of the MA(1), MA(2), and MA(3) processes. The results of the PM2.5 and $\mathrm{CO}$ air pollutant data indicate that the modified EWMA control chart was more effective than the standard one for detecting small shifts, and so confirms that it is excellent for monitoring unusual observations with undesirable values in a timely manner for all cases of exponential smoothing parameter.

The efficacy of the control charts was visualized by plotting graphs to showcase the effective results obtained from the proposed procedure in a comparative study. Fig. 1 shows that the modified EWMA control chart detected upper PM2.5 shifts at the $7^{\text {th }}$ to $11^{\text {th }}$ and $17^{\text {th }}$ to $21^{\text {st }}$ observations. On the other hand, the standard EWMA control chart only detected shifts at the $10^{\text {th }}$ to $26^{\text {th }}$ observations, as illustrated in Fig. 2. Fig. 3 exhibits that the modified EWMA chart detected upper $\mathrm{CO}$ level shifts at the $12^{\text {th }}, 25^{\text {th }}$ to $26^{\text {th }}$, and $30^{\text {th }}$ to $31^{\text {st }}$ observations. On the contrary, the original EWMA chart only detected upper CO level shifts at the $30^{\text {th }}$ to $31^{\text {st }}$ observations, as shown in Fig. 4.

The modified EWMA control chart detected the upper change in PM2.5 level at the $7^{\text {th }}$ observation (i.e. the $7^{\text {th }}$ January), which marked the beginning of extreme changes in PM2.5 emissions at the upper level. Meanwhile, the standard EWMA control chart detected the change at the $10^{\text {th }}$ observation (i.e. the $10^{\text {th }}$ January). Although the $\mathrm{CO}$ gas level emissions were low and harmless to the human body, the performance of the modified EWMA control chart for detecting the change in $\mathrm{CO}$ gas emissions was exemplary.

\section{Discussion}

The findings reveal that the modified EWMA control chart performed well for the case of smoothing parameter is greater than or equal to 0.1 due to the $R M I$ of the modified EWMA chart being less than the RMI of the EWMA chart.

When applied to real data, the modified EWMA control chart performed excellently for detecting shifts in the PM2.5 and CO pollution levels in all cases of smoothing parameter value. The smoothing parameter value of 0.1 is recommended in applications using the modified EWMA control chart. It is a good choice as it is easier to employ and performed better than the original EWMA control chart in all situations tested.

Peer] reviewing PDF | (2020:07:50582:5:0:NEW 4 Nov 2020) 


\section{Conclusions}

244 The exact ARL was provided by deriving explicit formulas that saved significantly on 245 computational time. Therefore, it is an excellent alternative for evaluating the ARL as a measure

246

247

248

249

250

251

252

253

254

255

256

257

258

259

260

261

262

263

264

265

266

267

268

269

270

271

272

273

274

275

276

277

278

279

280

281

282

283

284

285

286 of the effectiveness of the modified EWMA control chart. The technique showed good aptitude in monitoring and detecting small process shifts, as illustrated by changes in PM2.5 and CO gas levels examples comprising autocorrelated observations fitted to MA(2) and MA(3) models with exponential white noise. The empirical ARL shows that a smoothing parameter value of 0.1 to 0.2 supported the modified EWMA control chart far better than the EWMA control chart for all cases. Therefore, determination of the correct smoothing parameter of the chart should not be disregarded.

\section{References}

Al-Rashed A, Al-Mutairi N, Attar MA. 2019. Air pollution Analysis in Kuwait Using a Statistical Technique (CUSUM). International Journal of Geosciences 10:254-294.

Aslam M, Anwar SM. 2020. An improved Bayesian Modified EWMA location chart and its applications in mechanical and sport industry. Plos One 15:e229422.

Aslam M, Saghir A, Ahmad L, Jun CH, Hussain J. 2017. A control chart for COM-Poisson distribution using a modified EWMA statistic. Journal of Statistical Computation and Simulation Doi:10.1080/00949655.2017.1373114.

Barratt B, Atkinson R, Anderson HR, Beevers S, Kelly F, Mudway I, Wilkinson P. 2007. Investigation into the use of the CUSUM technique in identifying changes in mean air pollution levels following introduction of a traffic management scheme. Atmospheric Environment 41:1784-1791.

Carslaw DC, Ropkins K, Bell MC. 2006. Change-Point Detection of Gaseous and Particulate Traffic-Related Pollutants at a Roadside Location. Environmental Science \& Technology 40:6912-6918.

Carson PK, Yeh AB. 2008. Exponentially weighted moving average (EWMA) control charts for monitoring an analytical Process. Industrial \& Engineering Chemistry Research 47:405411.

Champ CW, Rigdon SE. 1991. A comparison of the Markov Chain and the Integral Equation Approaches for Evaluating the Run Length Distribution of Quality Control Charts. Communications in Statistics Simulation and Computation 20:191-204.

Chelani AB. 2011. Change detection using CUSUM and modified CUSUM method in air pollutant concentrations at traffic site in Delhi. Stochastic Environmental Research and Risk Assessment 25:827-834.

Cheong KH, Ngiam NJ, Morgan GG, Pek PP, Tan BYQ, Lai JW, Koh JM, Ong MEH, Ho AFW. 2019. Acut Health Impacts of the Southeast Asian Transbounday Haze Problem-A Review. International Journal of Environmental Research and Public Health 16:3286.

Chuersuwan N, Nimrat S, Lekphet S, Kerdkumrai T. 2008. Levels and major sources of PM2.5 and PM10 in Bangkok metropolitan region. Environmental International 34:671-677.

Han SW, Tsui K, Ariyajunya B, Kim SB. 2010. A comparison of CUSUM, and Temporal Scan Statistics for Detection of Increased in Poisson Rates. Quality and Reliability Engineering International 26:279-289.

He G, Lui T, Zhou M. 2020. Straw burning PM2.5, and death: Evidence from China. Journal of Development Economics 145:102468. 
287

288

289

290

291

292

293

294

295

296

297

298

299

300

301

302

303

304

305

306

307

308

309

310

311

312

313

314

315

316

317

318

319

320

321

322

323

324

325

326

327

328

329

Health Effects Institute. 2019. State of Global Air 2018 Special Report. Health EffectsInstitute, Boston, MA. http://challengingheights.org/wpcontent/uploads/2014/10/National_Analytical_ Report2010.pdf. (Accessed 27 February 2018)

Herdiani ET, Fandrilla G, Sunnsi Nurtiti. 2018. Modified Exponential Weighted Moving Average (EWMA) Control Chart on Autocorrelation Data. Journal of Physics Conference Series 979:012097.

Hua Y, Cheng Z, Wang S, Jiang J, Chen D, Cai S, Fu X, Fu Q, Chen C, Xu B, Yu J. 2015. Characteristics and source apportionment of PM2.5 during a fall heavy haze episode in the Yangtze River Delta of China. Atmospheric Environment 123: 380-391.

Huang XHH, Bian Q, Ng WM, Louie PKK, Yu JZ. 2014. Characterization of PM2.5 Major Components and Source Investigation in Suburban Hong Kong: A one Year Monitoring Study. Aerosol and Air Quality Research 14:237-250.

Jiang W, Tsui KL, Woodall WH. 2000. A new SPC monitoring method: The ARMA chart. Technometrics 42:399-410.

Johnston HJ, Mueller W, Steinle S, Vardoulakis S, Tantrakarnnapa K, Loh M, Cherrie JW. 2019. How Harmful Is Particulate Matter Emitted from Biomass Burning? A Thailand Perspective. Current Pollution Reports 5:353-377.

Khan N, Aslam M, Jun C. 2017. Design of a Control Chart Using a Modified EWMA Statistic. Quality and Reliability Engineering International 41:100-114.

Khan N, Yasmin T, Aslam M, Jun CH. 2018. On the performance of modified EWMA chart using resampling schemes. Operations Research and Decision 3:29-43.

Lee HH, Iraqui O, Gu Y, Yim SHL, Chulakadabba A, Tonks AYM, Yang Z, Wang C. 2018. Impacts of air pollutants from fire and non-fire emissions on the regional air quality in Southeast Asia. Atmospheric Chemistry and Physics 18:6141-6156.

Li J, Hu Y, Liu L, Wang Q, Zeng J. Chen C. 2020. PM2.5 exposure perturbs lung microbiome and its metabolic profilein mice. Science of the Total Environment 721: 137432.

Liao Z, Eie J, Sun P. 2020. The impact of particulate matter (PM2.5) on skin barrier revealed bytranscriptome analysis: Focusing on cholesterol metabolism. Toxicology Reports 7:1-9.

Mahidol University. 2020. PM2.5 Exposure and Health Management Measures for Thai Population, Faculty of Engineering, Bangkok, Thailand. https://www.eg.mahidol.ac.th/egmu _eng/news-events/events/218-pm-2-5-exposure-and-health-management-measures-for-thethai-pop pulation\#.

Manisalidis I, Stavropoulou E, Stavropoulos A, Bezirtzoglou E. 2020. Environmental and Health Impacts of Air Pollution: A Review. Frontiers in public health 8:14.

Noiplab T, Mayureesawan T. 2019. Modified EWMA Control Chart for Skewed Distributions and Contaminated Process. Thailand Statistician 17:16-29.

Oanh NTK, Kongpran J, Hang NT, Parkpian P, Hung NTQ, Lee SB, Bae GN. 2013. Characterization of gaseous pollutants and PM2.5 at fixed roadsides and along vehicle traveling routes in Bangkok metropolitan Region. Atmospheric Environment 77:674-685.

Page ES. 1954. Continuous Inspection Schemes. Biometrika 41:100-115.

Patel AK, Divecha J. 2011. Modified Exponentially Weighted Moving Average (EWMA) Control Chart for an Analytical Process Data. Journal of Chemical Engineering and Materials Science 2:12-20. 
330

331

332

333

334

335

336

337

338

339

340

341

342

343

344

345

346

347

348

349

350

351

352

353

354

355

356

357

358

359

360

361

362

363

364

365

366

367

368

369

370

371

372

Pinichka C, Makka N, Sukkumnoed D, Chariyalertsak S, Inchai P, Bundhamcharoen K. 2017. Burden of disease attributed to ambient air pollution in Thailand: AGIS-base approach. PloS One 12:e189909.

Pui DY, Chen SC, Zuo Z. 2014. PM2.5 in China: Measurements, sources, visibility and health effects, and mitigation. Particuology 13:1-26.

Roberts SW. 1959. Control Chart Tests Based on Geometric Moving Average. Technometrics 1:239-250.

Saarikoski S, Teinila K, Timonen H, Aurela M, Laaksovirta T, Reyes F, Vasques Y, Oyala P, Artaxo P, Pennanen AS, Junttila S, Linnainmaa M, Salonen RO, Hillamo R. 2018. Particulate matter characteristics, dynamics, and sources in an underground mine. Aerosol Science and Technology 52:114-122.

Saghir A, Ahmad L, Aslam M. 2019. Modified EWMA control chart for transformed gamma data. Communications in Statistics - Simulation and Computation Doi: 10.1080/03610918. 2019.1619762.

Saghir A, Aslam M, Faraz A, Ahmad L, Heuchenne C. 2020. Monitoring process variation using modified EWMA. Quality and Reliability Engineering International 36:328-339.

Shaddick G, Thomas ML, Mudu P, Ruggeri G, Gumy S. 2020. Half the world's population are exposed to increasing air pollution. npj Climate and Atmospheric Science 23:1-5.

Sofonea M, Han W, Shillor M. 2006. Analysis and Approximation of Contact Problems with Adhesion or Damage. Chapman \& Hall/CRC, New York.

Srivastava MS, WU YH. 1993. Comparison of EWMA, CUSUM and Shiryayev-Roberts procedures for detecting a shift in the mean. The Annals of Statistics 21:645-670.

Supharakonsakun Y, Areepong Y, Sukparungsee S. 2020. The exact solution of the average run length on a modified EWMA control chart for the first-order moving-average process. ScienceAsia 46:109-118.

Tian YZ, Shi GL, Han B, Wu JH, Zhou XY, Zhou LD, Zhang P, Feng YC. 2015. Using an improved source directional apportionment method to quantify the PM2.5 source contributions from various directions in a megacity in China. Chemosphere 122:270-283.

Wardell DG, Moskowitz H, Plante RD. 1994. Run-length distributions of special cause control charts for correlated processes (with discussion). Technometrics 36:3-27.

Wimolwattanapun W, Hopke PK, Pongkiatkul P. 2011. Source apportionment and potential source locations of PM2.5 and PM2.5-10 at residential sites in metropolitan Bangkok. Atmospheric Pollution Research 2:172-181.

Xing Y, Xu Y, Shi M, Lian Y. 2016. The impact of PM2.5 on the human respiratory system. Journal of Thoracic Disease 8:E69-E74.

Xu M-X, Ge C-X, Li Q, Lou D-S, Hu L-F, Sun Y, Xiong M-X, Lai L-L, Zhong S-Y, Yi C, Wang B-C, Tan J. 2020. Fisetin nanoparticles protect against PM2.5 exposure-induced neuroinflammation by down-regulation of astrocytes activation related NF-kB signaling pathway. Journal of Functional Foods 65:103716.

\section{Appendix A1: Derivation ARL for MA(q) process}

According to an MA(q) process in the Equation (9) as follows:

$$
X_{t}=\mu+\varepsilon_{t}-\theta_{1} \varepsilon_{t-1}-\theta_{2} \varepsilon_{t-2}-\ldots-\theta_{q} \varepsilon_{t-q},
$$

Therefore, the modified EWMA statistic for an MA(q) model can be written as

Peer) reviewing PDF | (2020:07:50582:5:0:NEW 4 Nov 2020) 


$$
\begin{aligned}
Z_{t}= & (1-\lambda) Z_{t-1}-X_{t-1}+(\lambda+k) \varepsilon_{t}+(\lambda+k) \mu-\left(\lambda \theta_{1}+\theta_{1} k\right) \varepsilon_{t-1}- \\
& \left(\lambda \theta_{2}+\theta_{2} k\right) \varepsilon_{t-2}-\ldots-\left(\lambda \theta_{q}+\theta_{q} k\right) \varepsilon_{t-q}
\end{aligned}
$$

373 where $\mathrm{t}=1,2,3, \ldots$, the initial value in the process mean $Z_{0}=u, X_{0}=v, \varepsilon_{0}=s$, and we use one 374 side of the control limit (i.e. $L C L=0$ and $U C L=$ b). Thus, we can obtain

$$
Z_{1}=(1-\lambda) u-v+(\lambda+k) \varepsilon_{1}+(\lambda+k) \mu-\left(\lambda \theta_{1}+\theta_{1} k\right) s-\ldots-\left(\lambda \theta_{q}+\theta_{q} k\right) \varepsilon_{1-q} .
$$

375

376

377

378

379

380

381

382

383

384

385

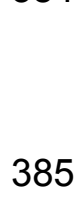

386

387

388

389

390

391

392

393

If $X_{1}$ causes the out-of-control state for $Z_{1}$, then

$$
(1-\lambda) u-v+(\lambda+k) \varepsilon_{1}+(\lambda+k) \mu-\left(\lambda \theta_{1}+\theta_{1} k\right) s-\ldots-\left(\lambda \theta_{q}+\theta_{q} k\right) \varepsilon_{1-q}>b
$$

or $(1-\lambda) u-v+(\lambda+k) \varepsilon_{1}+(\lambda+k) \mu-\left(\lambda \theta_{1}+\theta_{1} k\right) s-\ldots-\left(\lambda \theta_{q}+\theta_{q} k\right) \varepsilon_{1-q}<0$.

If $X_{1}$ causes the in-control state for $Z_{1}$, then

$$
0<(1-\lambda) u-v+(\lambda+k) \varepsilon_{1}+(\lambda+k) \mu-\left(\lambda \theta_{1}+\theta_{1} k\right) s-\ldots-\left(\lambda \theta_{q}+\theta_{q} k\right) \varepsilon_{t-q}<b .
$$

This can be written in the form

$$
\frac{-(1-\lambda) u+v-(\lambda+k) \mu+\left(\lambda \theta_{1}+\theta_{1} k\right) s+\ldots+\left(\lambda \theta_{q}+\theta_{q} k\right) \varepsilon_{t-q}}{\lambda+k}<\varepsilon_{1}<\frac{b-(1-\lambda) u+v-(\lambda+k) \mu+\left(\lambda \theta_{1}+\theta_{1} k\right) s+\ldots+\left(\lambda \theta_{q}+\theta_{q} k\right) \varepsilon_{t-q}}{\lambda+k} \text {. }
$$

The probability that $\varepsilon_{1}$ satisfies the bounds mentioned above for probability distribution function $\varepsilon_{t}$ is given as follows:

$P\left(\frac{-(1-\lambda) u+v-(\lambda+k) \mu+\left(\lambda \theta_{1}+\theta_{1} k\right) s+\ldots+\left(\lambda \theta_{q}+\theta_{q} k\right) \varepsilon_{t-q}}{\lambda+k}<\varepsilon_{1}<\frac{b-(1-\lambda) u+v-(\lambda+k) \mu+\left(\lambda \theta_{1}+\theta_{1} k\right) s+\ldots+\left(\lambda \theta_{q}+\theta_{q} k\right) \varepsilon_{t-q}}{\lambda+k}\right)$

$\frac{b-(1-\lambda) u+v-(\lambda+k) \mu+\left(\lambda \theta_{1}+\theta_{1} k\right) s+\ldots+\left(\lambda \theta_{q}+\theta_{q} k\right) \varepsilon_{t-q}}{\lambda+k}$

$$
=\int_{\frac{-(1-\lambda) u+v-(\lambda+k) \mu+\left(\lambda \theta_{1}+\theta_{1} k\right) s+\ldots+\left(\lambda \theta_{q}+\theta_{q} k\right) \varepsilon_{t-q}}{\lambda+k}}^{\lambda+k} f(y) d y .
$$

According to the method of Champ and Rigdon (1991), let $L(u)$ denote the ARL on a modified EWMA chart for an MA(q) process. We can write the integral equation in the form

$$
L(u)=1+\int_{\frac{-(1-\lambda) u+v-(\lambda+k) \mu+\left(\lambda \theta_{1}+\theta_{1} k\right) s+\ldots+\left(\lambda \theta_{q}+\theta_{q} k\right) \varepsilon_{1-q}}{\lambda+k}}^{\frac{b-(1-\lambda) u+v-(\lambda+k) \mu+\left(\lambda \theta_{1}+\theta_{1} k\right) s+\ldots+\left(\lambda \theta_{q}+\theta_{q} k\right) \varepsilon_{1-q}}{\lambda+k}} L\left[\begin{array}{l}
(1-\lambda) u-v+(\lambda+k) y+(\lambda+k) \mu- \\
\left(\lambda \theta_{1}+\theta_{1} k\right) s-\ldots-\left(\lambda \theta_{q}+\theta_{q} k\right) \varepsilon_{t-q}
\end{array}\right] f(y) d y .
$$

By changing the integral variable:

$g=(1-\lambda) u-v+(\lambda+k) y+(\lambda+k) \mu-\left(\lambda \theta_{1}+\theta_{1} k\right) s-\left(\lambda \theta_{2}+\theta_{2} k\right) \varepsilon_{t-2}-\ldots-\left(\lambda \theta_{q}+\theta_{q} k\right) \varepsilon_{t-q}$,

we obtain

$$
L(u)=1+\frac{1}{\lambda+k} \int_{0}^{b} L(g) f\left(\frac{g-(1-\lambda) u+v+\left(\lambda \theta_{1}+\theta_{1} k\right) s+\left(\lambda \theta_{2}+\theta_{2} k\right) \varepsilon_{t-2}+\ldots+\left(\lambda \theta_{q}+\theta_{q} k\right) \varepsilon_{t-q}}{\lambda+k}-\mu\right) d g .
$$

In this study, we define $\varepsilon_{t}$ is a white noise process and assumed that it is exponentially distributed with parameter $\alpha$. Therefore, the $L(u)$ is a Fredholm integral equation of the second kind as follow: 


$$
L(u)=1+\frac{1}{\lambda+k} \int_{0}^{b} L(g) \frac{1}{\alpha} e^{-\frac{g-(1-\lambda) u+v+\left(\lambda \theta_{1}+\theta_{1} k\right) s+\left(\lambda \theta_{2}+\theta_{2} k\right) \varepsilon_{t-2}+\ldots+\left(\lambda \theta_{q}+\theta_{q} k\right) \varepsilon_{t-q}}{\alpha(\lambda+k)}+\frac{\mu}{\alpha}} d g
$$

394 which becomes

$$
L(u)=1+\frac{e^{\frac{(1-\lambda) u-v-\left(\lambda \theta_{1}+\theta_{1} k\right) s-\left(\lambda \theta_{2}+\theta_{2} k\right) \varepsilon_{t-2}+\ldots+\left(\lambda \theta_{q}+\theta_{q} k\right) \varepsilon_{t-q}}{\alpha(\lambda+k)}+\frac{\mu}{\alpha}}}{\alpha(\lambda+k)} \int_{0}^{b} L(g) \cdot e^{-\frac{g}{\alpha(\lambda+k)}} d g .
$$

$395 \quad$ Suppose that

$$
C(u)=e^{\frac{(1-\lambda) u-v-\left(\lambda \theta_{1}+\theta_{1} k\right) s-\left(\lambda \theta_{2}+\theta_{2} k\right) \varepsilon_{t-2}+\ldots+\left(\lambda \theta_{q}+\theta_{q} k\right) \varepsilon_{t-q}}{\alpha(\lambda+k)}+\frac{\mu}{\alpha}}, 0 \leq u \leq b
$$

396 and

$$
D=\int_{0}^{b} L(g) \cdot e^{-\frac{g}{\alpha(\lambda+k)}} d g, \text { where } D \text { is a constant. }
$$

Thus, we can obtain

$$
L(u)=1+\frac{C(u)}{\alpha(\lambda+k)} D
$$

The ARL for an MA(q) process on a modified EWMA control chart is obtained by deriving 399 a Fredholm integral equation of the second kind as follows:

$$
L(u)=1-\frac{\lambda e^{\frac{(1-\lambda) u}{\alpha_{0}(\lambda+k)}}\left[e^{-\frac{b}{\alpha_{0}(\lambda+k)}}-1\right]}{\lambda e^{\frac{-\mu}{\alpha_{0}}} \cdot e^{\frac{v+\left(\lambda \theta_{1}+\theta_{1} k\right) s+\left(\lambda \theta_{2}+\theta_{2} k\right) \varepsilon_{t-2}+\ldots+\left(\lambda \theta_{q}+\theta_{q} k\right) \varepsilon_{t-q}}{\alpha_{0}(\lambda+k)}}+e^{-\frac{\lambda b}{\alpha_{0}(\lambda+k)}}-1},
$$

400

401

402

403

404

405

406

407

408

409

with in-control process parameter $\alpha_{0}$ and out-of-control process parameter $\alpha_{1}>\alpha_{0}$.

\section{Appendix A2: Existence and Uniqueness of ARLs}

The Banach's Fixed-point Theorem is used to show the exists and a uniqueness of the solution for ARL using the integral equation for the explicit formulas.

Let $M \neq \varnothing$ be a complete metric space and $d: M \times M \rightarrow R . d$ is a distance function on $M$ such that the following axioms hold.

1. $d(x, y) \geq 0$ for all $x, y \in M$

2. $d(x, y)=0$ if and only if $x=y$

3. $d(x, y)=d(y, x) \leftrightarrow x=y$ for all $x, y \in M$

4. $d(x, y) \leq d(x, z)+d(z, y)$ for all $x, y, z \in M$. 
410

411

412 413

414

415

416

417

418

419

420

421

422

423

424

425

426

427

428

429

430

431

432

25

Since $(M, \mathrm{~d})$ is a complete metric space, it denoted the space of all continuous function on $[0, b]$ with the norm $\|\cdot\|_{\infty}=\sup _{u \in I}|L(u)|$ and every Cauchy's sequence $\left\{L_{n}\right\}_{n \geq 0}$ for a point of $M$ converges to a point $L_{0} \in[0, b]$. In this case, let $T$ be an operation in the class of all continuous functions defined by,

$$
T(L(u))=1+\frac{1}{\lambda+k} \int_{0}^{b} L(g) \frac{1}{\alpha} e^{-\frac{g-(1-\lambda) u+v+\left(\lambda \theta_{1}+\theta_{1} k\right) s+\left(\lambda \theta_{2}+\theta_{2} k\right) \varepsilon_{t-2}+\ldots+\left(\lambda \theta_{q}+\theta_{q} k\right) \varepsilon_{t-q}}{\alpha(\lambda+k)}+\frac{\mu}{\alpha}} d g .
$$

By Banach's Fixed-point Theorem, if an operator $T$ is a contraction, then the fixed-point equation $T(L(u))=L(u)$ has a unique solution. The equation (20) exists and has a unique solution according to the following the theorem.

Theorem 1. (Banach's Fixed-point Theorem)

Let $(M, \mathrm{~d})$ be a complete metric space and $T: M \rightarrow M$ be a contraction mapping with contraction constant $c \in[0,1)$ such that $\left\|T\left(L_{1}\right)-T\left(L_{2}\right)\right\| \leq c\left\|L_{1}-L_{2}\right\|$ for all $L_{1}, L_{2} \in M$. Subsequently, there exists a unique $L(.) \in X$ such that $T(L(u))=L(u)$ (Sofonea et al., 2006).

Proof. The inequality

$\left\|T\left(L_{1}\right)-T\left(L_{2}\right)\right\| \leq c\left\|L_{1}-L_{2}\right\|$ for all $L_{1}, L_{2} \in[0, b]$ with $0 \leq c<1$.

Consider equation (14),

$\left\|T\left(L_{1}\right)-T\left(L_{2}\right)\right\|=\sup _{u \in[0, b]}|L(u)|$

$$
\begin{aligned}
& =\sup _{u \in[0, b]}\left|\left(L_{1}(g)-L_{2}(g)\right) \frac{1}{\lambda+k} \int_{0}^{b} L(g) \frac{1}{\alpha} e^{-\frac{g-(1-\lambda) u+v+\left(\lambda \theta_{1}+\theta_{1} k\right) s+\left(\lambda \theta_{2}+\theta_{2} k\right) \varepsilon_{t-2}+\ldots+\left(\lambda \theta_{q}+\theta_{q} k\right) \varepsilon_{t-q}}{\alpha(\lambda+k)}+\frac{\mu}{\alpha}} d g\right| \\
& \leq \sup _{u \in[0, b]}|| L_{1}-L_{2} \|_{\infty} \frac{-\alpha(\lambda+k)}{\alpha(\lambda+k)} e^{\frac{(1-\lambda) u-v-\left(\lambda \theta_{1}+\theta_{1} k\right) s-\left(\lambda \theta_{2}+\theta_{2} k\right) \varepsilon_{t-2}-\ldots-\left(\lambda \theta_{q}+\theta_{q} k\right) \varepsilon_{t-q}}{\alpha(\lambda+k)}+\frac{\mu}{\alpha}}\left[e^{\frac{-b}{\alpha(\lambda+k)}}-1\right] \mid \\
& =\left\|L_{1}-L_{2}\right\|_{\infty} \mid 1-e^{\frac{-b}{\alpha(\lambda+k)}\left|\sup _{u \in[0, b]}\right| e^{\frac{(1-\lambda) u-v-\left(\lambda \theta_{1}+\theta_{1} k\right) s-\left(\lambda \theta_{2}+\theta_{2} k\right) \varepsilon_{t-2}-\ldots-\left(\lambda \theta_{q}+\theta_{q} k\right) \varepsilon_{t-q}}{\alpha(\lambda+k)}+\frac{\mu}{\alpha}} \mid}
\end{aligned}
$$$$
=c\left\|L_{1}-L_{2}\right\|_{\infty},
$$

where $c=\left|1-e^{\frac{-b}{\alpha(\lambda+k)}}\right| \sup _{u \in[0, b]}\left|e^{\frac{(1-\lambda) u-v-\left(\lambda \theta_{1}+\theta_{1} k\right) s-\left(\lambda \theta_{2}+\theta_{2} k\right) \varepsilon_{t-2}-\ldots-\left(\lambda \theta_{q}+\theta_{q} k\right) \varepsilon_{t-q}}{\alpha(\lambda+k)}+\frac{\mu}{\alpha}}\right| ; 0 \leq c<1$ and $c$ is a positive constant.

By Theorem 1, Banach's Fixed-point Theorem guarantees the existence and uniqueness of the solution for the ARL. 


\section{Table 1 (on next page)}

The ARL of explicit formulas and NIE method for $\mathrm{MA}(2)$ when $\mathrm{mu}=2$ and $k=1$ on modified EWMA control chart. 
1 Table 1 The ARL of explicit formulas and NIE method for MA(2) when $\mu=2$ and $k=1$ on 2 modified EWMA control chart.

\begin{tabular}{|c|c|c|c|c|c|c|}
\hline$\lambda$ & $\theta_{i}$ & $b$ & $\delta$ & Explicit & NIE & $\varepsilon$ \\
\hline \multirow{9}{*}{0.05} & \multirow{9}{*}{$\begin{aligned} \theta_{1} & =-0.3 \\
\theta_{2} & =0.5\end{aligned}$} & \multirow{9}{*}{0.4528820782} & 0.00 & 500.000070 & 500.000063 & $1.249 \times 10^{-6}$ \\
\hline & & & 0.001 & 344.029967 & 344.029963 & $1.098 \times 10^{-6}$ \\
\hline & & & 0.003 & 211.859210 & 211.859208 & $9.666 \times 10^{-7}$ \\
\hline & & & 0.005 & 153.059939 & 153.059937 & $9.058 \times 10^{-7}$ \\
\hline & & & 0.01 & 90.369435 & 90.369435 & $8.348 \times 10^{-7}$ \\
\hline & & & 0.05 & 21.191203 & 21.191203 & $6.871 \times 10^{-7}$ \\
\hline & & & 0.10 & 10.915019 & 10.915019 & $5.891 \times 10^{-7}$ \\
\hline & & & 0.50 & 2.615077 & 2.615077 & $2.141 \times 10^{-7}$ \\
\hline & & & 1.00 & 1.693016 & 1.693016 & $8.269 \times 10^{-8}$ \\
\hline \multirow{9}{*}{0.1} & \multirow{9}{*}{$\begin{aligned} \theta_{1} & =-0.3 \\
\theta_{2} & =0.5\end{aligned}$} & \multirow{9}{*}{0.45905302} & 0.00 & 500.000081 & 500.000068 & $2.634 \times 10^{-6}$ \\
\hline & & & 0.001 & 334.507743 & 334.507737 & $1.996 \times 10^{-6}$ \\
\hline & & & 0.003 & 201.308260 & 201.308257 & $1.479 \times 10^{-6}$ \\
\hline & & & 0.005 & 144.002910 & 144.002908 & $1.254 \times 10^{-6}$ \\
\hline & & & 0.01 & 84.171367 & 84.171366 & $1.014 \times 10^{-6}$ \\
\hline & & & 0.05 & 19.612599 & 19.612599 & $6.883 \times 10^{-7}$ \\
\hline & & & 0.10 & 10.146990 & 10.146990 & $5.686 \times 10^{-7}$ \\
\hline & & & 0.50 & 2.508587 & 2.508587 & $1.953 \times 10^{-7}$ \\
\hline & & & 1.00 & 1.653220 & 1.653220 & $7.259 \times 10^{-8}$ \\
\hline \multirow{9}{*}{0.15} & \multirow{9}{*}{$\begin{array}{l}\theta_{1}=0.1 \\
\theta_{2}=0.3\end{array}$} & \multirow{9}{*}{0.572945976} & 0.00 & 500.000144 & 500.000105 & $7.802 \times 10^{-6}$ \\
\hline & & & 0.001 & 334.491414 & 334.491395 & $5.543 \times 10^{-6}$ \\
\hline & & & 0.003 & 201.328130 & 201.328122 & $3.721 \times 10^{-6}$ \\
\hline & & & 0.005 & 144.051692 & 144.051688 & $2.934 \times 10^{-6}$ \\
\hline & & & 0.01 & 84.258340 & 84.258339 & $2.104 \times 10^{-6}$ \\
\hline & & & 0.05 & 19.742557 & 19.742557 & $1.116 \times 10^{-6}$ \\
\hline & & & 0.10 & 10.274933 & 10.274932 & $8.711 \times 10^{-7}$ \\
\hline & & & 0.50 & 2.592448 & 2.592448 & $2.893 \times 10^{-7}$ \\
\hline & & & 1.00 & 1.709825 & 1.709825 & $1.053 \times 10^{-7}$ \\
\hline \multirow{9}{*}{0.2} & \multirow{9}{*}{$\begin{array}{l}\theta_{1}=0.1 \\
\theta_{2}=0.3\end{array}$} & \multirow{9}{*}{0.583106542} & 0.00 & 500.000089 & 500.000024 & $1.309 \times 10^{-5}$ \\
\hline & & & 0.001 & 326.638522 & 326.638494 & $8.859 \times 10^{-6}$ \\
\hline & & & 0.003 & 192.985129 & 192.985118 & $5.595 \times 10^{-6}$ \\
\hline & & & 0.005 & 137.017229 & 137.017224 & $4.225 \times 10^{-6}$ \\
\hline & & & 0.01 & 79.531204 & 79.531202 & $2.809 \times 10^{-6}$ \\
\hline & & & 0.05 & 18.554510 & 18.554510 & $1.219 \times 10^{-6}$ \\
\hline & & & 0.10 & 9.693785 & 9.693784 & $9.119 \times 10^{-7}$ \\
\hline & & & 0.50 & 2.508174 & 2.508174 & $2.751 \times 10^{-7}$ \\
\hline & & & 1.00 & 1.677336 & 1.677336 & $1.014 \times 10^{-7}$ \\
\hline
\end{tabular}

3 Where $\lambda$ is a smoothing parameter, $\theta_{i}$ is a process coefficient, $b$ is UCL, $\delta$ is the shift size and $4 \varepsilon$ is the relative error. 


\section{Table 2 (on next page)}

The ARL of explicit formulas and NIE method for MA(3) when mu=2 and $k=1$ on modified EWMA control chart. 
1 Table 2 The ARL of explicit formulas and NIE method for MA(3) when $\mu=2$ and $k=1$ on 2 modified EWMA control chart.

\begin{tabular}{|c|c|c|c|c|c|c|}
\hline$\lambda$ & $\theta_{i}$ & $b$ & $\delta$ & Explicit & NIE & $\varepsilon$ \\
\hline \multirow{9}{*}{0.05} & & \multirow{9}{*}{1.7145985314} & 0.00 & 500.000035 & 499.999925 & $2.200 \times 10^{-5}$ \\
\hline & & & 0.001 & 416.626140 & 416.226056 & $2.013 \times 10^{-5}$ \\
\hline & & & 0.003 & 312.391104 & 312.391049 & $1.777 \times 10^{-5}$ \\
\hline & $\theta_{1}=0.3$ & & 0.005 & 249.841554 & 249.841513 & $1.634 \times 10^{-5}$ \\
\hline & $\theta_{2}=0.5$ & & 0.01 & 166.435290 & 166.435266 & $1.437 \times 10^{-5}$ \\
\hline & $\theta_{3}=0.7$ & & 0.05 & 45.160512 & 45.160507 & $1.073 \times 10^{-5}$ \\
\hline & & & 0.10 & 23.579116 & 23.579114 & $9.196 \times 10^{-6}$ \\
\hline & & & 0.50 & 5.145761 & 5.145761 & $4.015 \times 10^{-6}$ \\
\hline & & & 1.00 & 2.933150 & 2.933150 & $1.841 \times 10^{-6}$ \\
\hline \multirow{9}{*}{0.1} & & \multirow{9}{*}{1.790036614} & 0.00 & 500.000093 & 499.999812 & $5.633 \times 10^{-5}$ \\
\hline & & & 0.001 & 412.884959 & 412.884760 & $4.831 \times 10^{-5}$ \\
\hline & & & 0.003 & 306.166728 & 306.166611 & $3.847 \times 10^{-5}$ \\
\hline & $\theta_{1}=0.3$ & & 0.005 & 243.266257 & 243.266177 & $3.265 \times 10^{-5}$ \\
\hline & $\theta_{2}=0.5$ & & 0.01 & 160.685954 & 160.685914 & $2.495 \times 10^{-5}$ \\
\hline & $\theta_{3}=0.7$ & & 0.05 & 43.171580 & 43.171574 & $1.322 \times 10^{-5}$ \\
\hline & & & 0.10 & 22.563452 & 22.563449 & $1.031 \times 10^{-6}$ \\
\hline & & & 0.50 & 5.001808 & 5.001808 & $4.065 \times 10^{-6}$ \\
\hline & & & 1.00 & 2.881284 & 2.881284 & $1.833 \times 10^{-6}$ \\
\hline \multirow{9}{*}{0.15} & & \multirow{9}{*}{0.10145919916} & 0.00 & 500.000074 & 500.000073 & $2.124 \times 10^{-6}$ \\
\hline & & & 0.001 & 270.407899 & 270.407899 & $1.293 \times 10^{-6}$ \\
\hline & & & 0.003 & 140.988209 & 140.988209 & $8.213 \times 10^{-7}$ \\
\hline & $\theta_{1}=-0.5$ & & 0.005 & 95.372295 & 95.372295 & $6.522 \times 10^{-7}$ \\
\hline & $\theta_{2}=-0.3$ & & 0.01 & 52.755839 & 52.755839 & $4.928 \times 10^{-7}$ \\
\hline & $\theta_{3}=-0.5$ & & 0.05 & 11.649752 & 11.649752 & $3.004 \times 10^{-7}$ \\
\hline & & & 0.10 & 6.024879 & 6.024879 & $2.324 \times 10^{-7}$ \\
\hline & & & 0.50 & 1.671266 & 1.671266 & $5.983 \times 10^{-8}$ \\
\hline & & & 1.00 & 1.247145 & 1.247145 & $0.000 \times 10^{-7}$ \\
\hline \multirow{9}{*}{0.2} & & \multirow{9}{*}{0.1023254883} & 0.00 & 500.000023 & 500.000021 & $3.506 \times 10^{-6}$ \\
\hline & & & 0.001 & 260.636834 & 260.636833 & $1.964 \times 10^{-6}$ \\
\hline & & & 0.003 & 133.218384 & 133.218384 & $1.140 \times 10^{-6}$ \\
\hline & $\theta_{1}=-0.5$ & & 0.005 & 89.517777 & 89.517777 & $8.557 \times 10^{-7}$ \\
\hline & $\theta_{2}=-0.3$ & & 0.01 & 49.241334 & 49.241334 & $5.910 \times 10^{-7}$ \\
\hline & $\theta_{3}=-0.5$ & & 0.05 & 10.884204 & 10.884204 & $3.032 \times 10^{-7}$ \\
\hline & & & 0.10 & 5.670187 & 5.670187 & $2.293 \times 10^{-7}$ \\
\hline & & & 0.50 & 1.630976 & 1.630976 & $6.131 \times 10^{-8}$ \\
\hline & & & 1.00 & 1.234071 & 1.234071 & $0.000 \times 10^{-7}$ \\
\hline
\end{tabular}

3 Where $\lambda$ is a smoothing parameter, $\theta_{i}$ is a process coefficient, $b$ is UCL, $\delta$ is the shift size and $4 \varepsilon$ is the relative error. 


\section{Table 3(on next page)}

The ARL of explicit formulas and NIE method for MA(3) when $m u=2$, lambda $=0.1$ and $k=5$ lambda , 10 lambda , 20 lambda , 50 lambda on modified EWMA control chart. 
1 Table 3 The ARL of explicit formulas and NIE method for MA(3) when $\mu=2, \lambda=0.1$ and $k=$

$25 \lambda, 10 \lambda, 20 \lambda, 50 \lambda$ on modified EWMA control chart.

\begin{tabular}{|c|c|c|c|c|c|c|}
\hline $\boldsymbol{k}$ & $\theta_{i}$ & $b$ & $\delta$ & Explicit & NIE & $\varepsilon$ \\
\hline \multirow{9}{*}{$5 \lambda$} & & \multirow{9}{*}{0.3993899124} & 0.00 & 500.000066 & 500.000043 & $4.561 \times 10^{-6}$ \\
\hline & & & 0.001 & 413.570468 & 413.570451 & $4.083 \times 10^{-6}$ \\
\hline & & & 0.003 & 307.119823 & 307.119812 & $3.491 \times 10^{-6}$ \\
\hline & $\theta_{1}=-0.3$ & & 0.005 & 244.081098 & 244.081090 & $3.137 \times 10^{-6}$ \\
\hline & $\theta_{2}=0.7$ & & 0.01 & 160.988028 & 160.988024 & $2.660 \times 10^{-6}$ \\
\hline & $\theta_{3}=-0.5$ & & 0.05 & 42.170082 & 42.170082 & $1.846 \times 10^{-6}$ \\
\hline & & & 0.10 & 21.358100 & 21.358099 & $1.552 \times 10^{-6}$ \\
\hline & & & 0.50 & 4.092363 & 4.092363 & $6.280 \times 10^{-7}$ \\
\hline & & & 1.00 & 2.254223 & 2.254223 & $2.573 \times 10^{-7}$ \\
\hline \multirow{9}{*}{$10 \lambda$} & & \multirow{9}{*}{0.3381621032} & 0.00 & 500.000057 & 500.000050 & $1.383 \times 10^{-6}$ \\
\hline & & & 0.001 & 322.652564 & 322.652560 & $1.028 \times 10^{-6}$ \\
\hline & & & 0.003 & 188.777532 & 188.777531 & $7.591 \times 10^{-7}$ \\
\hline & $\theta_{1}=-0.3$ & & 0.005 & 133.436625 & 133.436624 & $6.465 \times 10^{-7}$ \\
\hline & $\theta_{2}=0.7$ & & 0.01 & 77.030788 & 77.030787 & $5.282 \times 10^{-7}$ \\
\hline & $\theta_{3}=-0.5$ & & 0.05 & 17.693001 & 17.693001 & $3.662 \times 10^{-7}$ \\
\hline & & & 0.10 & 9.130173 & 9.130173 & $3.023 \times 10^{-7}$ \\
\hline & & & 0.50 & 2.283033 & 2.283033 & $1.007 \times 10^{-7}$ \\
\hline & & & 1.00 & 1.537883 & 1.537883 & $3.251 \times 10^{-8}$ \\
\hline \multirow{9}{*}{$20 \lambda$} & & \multirow{9}{*}{0.416955807} & 0.00 & 500.000064 & 500.000060 & $7.459 \times 10^{-7}$ \\
\hline & & & 0.001 & 259.369506 & 259.369504 & $4.634 \times 10^{-7}$ \\
\hline & & & 0.003 & 132.360364 & 132.360364 & $3.136 \times 10^{-7}$ \\
\hline & $\theta_{1}=-0.3$ & & 0.005 & 88.971221 & 88.971221 & $2.615 \times 10^{-7}$ \\
\hline & $\theta_{2}=0.7$ & & 0.01 & 49.057165 & 49.057164 & $2.118 \times 10^{-7}$ \\
\hline & $\theta_{3}=-0.5$ & & 0.05 & 11.092459 & 11.092459 & $1.451 \times 10^{-7}$ \\
\hline & & & 0.10 & 5.913303 & 5.913303 & $1.167 \times 10^{-7}$ \\
\hline & & & 0.50 & 1.796095 & 1.796095 & $3.341 \times 10^{-8}$ \\
\hline & & & 1.00 & 1.339172 & 1.339172 & $7.467 \times 10^{-9}$ \\
\hline \multirow{9}{*}{$50 \lambda$} & & \multirow{9}{*}{0.763809721} & 0.00 & 500.000067 & 500.000064 & $5.106 \times 10^{-7}$ \\
\hline & & & 0.001 & 218.076288 & 218.076288 & $2.735 \times 10^{-7}$ \\
\hline & & & 0.003 & 102.797634 & 102.797634 & $1.760 \times 10^{-7}$ \\
\hline & $\theta_{1}=-0.3$ & & 0.005 & 67.421706 & 67.421706 & $1.455 \times 10^{-7}$ \\
\hline & $\theta_{2}=0.7$ & & 0.01 & 36.459416 & 36.459416 & $1.174 \times 10^{-7}$ \\
\hline & $\theta_{1}=-0.5$ & & 0.05 & 8.314559 & 8.314559 & $7.938 \times 10^{-8}$ \\
\hline & & & 0.10 & 4.565969 & 4.565969 & $6.132 \times 10^{-8}$ \\
\hline & & & 0.50 & 1.588295 & 1.588295 & $1.889 \times 10^{-8}$ \\
\hline & & & 1.00 & 1.253079 & 1.253079 & $0.000 \times 10^{-8}$ \\
\hline
\end{tabular}

3 Where $\lambda$ is a smoothing parameter, $\theta_{i}$ is a process coefficient, $b$ is UCL, $\delta$ is the shift size and $4 \varepsilon$ is the relative error. 
Table 4 (on next page)

Comparison ARL for $M A(2)$ and $M A(3)$ when $m u=2$, (theta ${ }_{1}$, theta 2$)=(-0.1,-0.3)$, (theta ${ }_{1}$, theta ${ }_{2}$, theta $\left._{3}\right)=(0.7,0.7,-0.1)$ and $k=1$ on EWMA and modified EWMA control charts using by explicit formulas. 
1 Table 4 Comparison ARL for MA(2) and MA(3) when $\mu=2,\left(\theta_{1}, \theta_{2}\right)=(-0.1,-0.3),\left(\theta_{1}, \theta_{2}, \theta_{3}\right)$ $2=(0.7,0.7,-0.1)$ and $k=1$ on EWMA and modified EWMA control charts using by explicit 3 formulas.

\begin{tabular}{|c|c|c|c|c|}
\hline \multirow{3}{*}{$\begin{array}{c}\text { Shift size } \\
\quad(\delta)\end{array}$} & \multicolumn{4}{|c|}{ MA(2) } \\
\hline & \multicolumn{2}{|c|}{$\lambda=0.05$} & \multicolumn{2}{|c|}{$\lambda=\mathbf{0 . 1}$} \\
\hline & $\begin{array}{c}\text { EWMA } \\
\left(h=1.540947 \times 10^{-6}\right)\end{array}$ & $\begin{array}{c}\text { Modified } \\
(b=0.247244692) \\
\end{array}$ & $\begin{array}{c}\text { EWMA } \\
\left(h=9.722515 \times 10^{-2}\right)\end{array}$ & $\begin{array}{c}\text { Modified } \\
(b=0.2494786708)\end{array}$ \\
\hline 0.00 & 500.000084 & 500.000051 & 500.000053 & 500.000045 \\
\hline 0.001 & 491.302902 & 322.103642 & 496.493518 & 311.471395 \\
\hline 0.003 & 474.409028 & 188.165212 & 489.573629 & 177.579957 \\
\hline 0.005 & 458.159230 & 132.886351 & 482.775802 & 124.203548 \\
\hline 0.01 & 420.179693 & 76.597597 & 466.298614 & 70.932841 \\
\hline 0.05 & 216.581889 & 17.452224 & 357.212201 & 16.095125 \\
\hline 0.10 & 101.304137 & 8.935028 & 262.720549 & 8.288535 \\
\hline 0.30 & 9.326784 & 3.244020 & 96.241953 & 3.076188 \\
\hline 0.50 & 2.314971 & 2.182431 & 45.489101 & 2.100245 \\
\hline 1.00 & 1.062006 & 1.475103 & 13.178794 & 1.446133 \\
\hline 2.00 & 1.002599 & 1.189396 & 3.916046 & 1.179423 \\
\hline \multirow[t]{2}{*}{$R M I$} & 3.266348 & 0.057529 & 12.408089 & 0.000000 \\
\hline & \multicolumn{4}{|c|}{$\mathrm{MA}(3)$} \\
\hline Shift size & \multicolumn{2}{|c|}{$\lambda=\mathbf{0 . 1 5}$} & \multicolumn{2}{|c|}{$\lambda=\mathbf{0 . 2}$} \\
\hline$(\delta)$ & $\begin{array}{c}\text { EWMA } \\
(h=0.26180448)\end{array}$ & $\begin{array}{c}\text { Modified } \\
(b=1.495885499)\end{array}$ & $\begin{array}{c}\text { EWMA } \\
(h=0.48260591)\end{array}$ & $\begin{array}{c}\text { Modified } \\
(b=1.552310613)\end{array}$ \\
\hline 0.00 & 500.000023 & 500.000016 & 500.000059 & 500.000012 \\
\hline 0.001 & 497.068024 & 389.027511 & 497.491338 & 384.835986 \\
\hline 0.003 & 491.267689 & 269.482277 & 492.501520 & 263.538348 \\
\hline 0.005 & 485.551042 & 206.178820 & 487.548819 & 200.434640 \\
\hline 0.01 & 471.616385 & 129.968083 & 475.331533 & 125.474506 \\
\hline 0.05 & 376.298194 & 33.106525 & 386.389784 & 31.756669 \\
\hline 0.10 & 288.608113 & 17.342524 & 297.158447 & 16.662591 \\
\hline 0.30 & 117.137775 & 6.311771 & 113.435186 & 6.117180 \\
\hline 0.50 & 58.046820 & 4.096353 & 53.536263 & 3.995715 \\
\hline 1.00 & 17.466862 & 2.475941 & 15.918420 & 2.438029 \\
\hline 2.00 & 5.133009 & 1.705112 & 5.033017 & 1.691792 \\
\hline$R M I$ & 6.988635 & 0.000000 & 7.082964 & 0.000000 \\
\hline
\end{tabular}

4 Where $\lambda$ is a smoothing parameter, $b$ is UCL of the modified chart, and $h$ is UCL of the 5 EWMA chart. 


\section{Table 5 (on next page)}

Comparison ARL for MA(2) observations for PM2.5 in Thailand when mu=51.163, $\left(\right.$ theta ${ }_{1}$, theta $\left._{2}\right)=(-0.723,-0.380)$ and alpha $_{0}=8.90$ on EWMA and modified EWMA control charts using by explicit formulas. 
1 Table 5 Comparison ARL for MA(2) observations for PM2.5 in Thailand when $\mu=51.163,\left(\theta_{1}\right.$ $\left.2, \theta_{2}\right)=(-0.723,-0.380)$ and $\alpha_{0}=8.90$ on EWMA and modified EWMA control charts using by 3 explicit formulas.

\begin{tabular}{|c|c|c|c|c|}
\hline \multirow{2}{*}{$\begin{array}{c}\text { Shift size } \\
(\delta)\end{array}$} & \multicolumn{2}{|c|}{$\lambda=\mathbf{0 . 0 5}$} & \multicolumn{2}{|c|}{$\lambda=\mathbf{0 . 1}$} \\
\hline & $\begin{array}{c}\text { EWMA } \\
\left(h=4.2219 \times 10^{-5}\right)\end{array}$ & $\begin{array}{c}\text { Modified } \\
(b=0.02922099) \\
\end{array}$ & $\begin{array}{c}\text { EWMA } \\
(h=0.041728)\end{array}$ & $\begin{array}{c}\text { Modified } \\
(b=0.03046693)\end{array}$ \\
\hline 0.00 & 500.058819 & 500.062160 & 500.040155 & 500.049594 \\
\hline 0.001 & 499.135917 & 372.303952 & 499.464575 & 371.313138 \\
\hline 0.003 & 497.295828 & 246.500852 & 498.315774 & 245.210289 \\
\hline 0.005 & 495.463334 & 184.318545 & 497.170110 & 183.121388 \\
\hline 0.01 & 490.915098 & 113.156303 & 494.319608 & 112.261092 \\
\hline 0.05 & 456.167456 & 28.053250 & 472.201199 & 27.791251 \\
\hline 0.10 & 416.548214 & 14.711725 & 446.185321 & 14.575755 \\
\hline 0.30 & 292.467926 & 5.402048 & 357.803981 & 5.358236 \\
\hline 0.50 & 208.450137 & 3.507836 & 289.541426 & 3.483141 \\
\hline 1.00 & 94.976087 & 2.098796 & 176.853408 & 2.088303 \\
\hline 2.00 & 24.817914 & 1.428039 & 75.347531 & 1.424175 \\
\hline$R M I$ & 22.115534 & 0.000000 & 33.559477 & 0.000000 \\
\hline Shift size & \multicolumn{2}{|c|}{$\lambda=0.15$} & \multicolumn{2}{|c|}{$\lambda=0.2$} \\
\hline$(\delta)$ & $\begin{array}{c}\text { EWMA } \\
(h=0.211034)\end{array}$ & $\begin{array}{c}\text { Modified } \\
(b=0.03171369)\end{array}$ & $\begin{array}{c}\text { EWMA } \\
(h=0.305241)\end{array}$ & $\begin{array}{c}\text { Modified } \\
(b=0.03296119)\end{array}$ \\
\hline 0.00 & 500.037390 & 500.045701 & 500.042301 & 500.068733 \\
\hline 0.001 & 499.529929 & 370.409082 & 499.539394 & 369.591967 \\
\hline 0.003 & 498.516876 & 244.034940 & 498.535421 & 242.964923 \\
\hline 0.005 & 497.506311 & 182.033100 & 497.533895 & 181.042240 \\
\hline 0.01 & 494.990736 & 111.449184 & 495.040738 & 110.710551 \\
\hline 0.05 & 475.411216 & 27.554328 & 475.631720 & 27.339135 \\
\hline 0.10 & 452.240112 & 14.452853 & 452.652967 & 14.341252 \\
\hline 0.30 & 372.239132 & 5.318641 & 373.229915 & 5.282691 \\
\hline 0.50 & 308.827934 & 3.460822 & 310.167476 & 3.440555 \\
\hline 1.00 & 199.849984 & 2.078817 & 210.495325 & 2.070201 \\
\hline 2.00 & 93.953526 & 1.420680 & 95.355765 & 1.417504 \\
\hline$R M I$ & 37.060241 & 0.000000 & 37.933433 & 0.000000 \\
\hline
\end{tabular}

4 Where $\lambda$ is a smoothing parameter, $b$ is UCL of the modified chart, and $h$ is UCL of the 5 EWMA chart. 
Table 6(on next page)

Comparison ARL for MA(3) observations for $\mathrm{CO}$ gas in Thailand when $m u=1.198$, (theta ${ }_{1}$, theta $_{2}$, theta $\left._{3}\right)=(-0.662,-0.479,-0.495)$ and alpha $_{0}=0.1226$ on EWMA and modified EWMA control charts using by explicit formulas. 
1 Table 6 Comparison ARL for MA(3) observations for CO gas in Thailand when $\mu=1.198,\left(\theta_{1}\right.$,

$\left.2 \theta_{2}, \theta_{3}\right)=(-0.662,-0.479,-0.495)$ and $\alpha_{0}=0.1226$ on EWMA and modified EWMA control charts

3 using by explicit formulas.

\begin{tabular}{|c|c|c|c|c|}
\hline \multirow{2}{*}{$\begin{array}{c}\text { Shift size } \\
(\delta)\end{array}$} & \multicolumn{2}{|c|}{$\lambda=\mathbf{0 . 0 5}$} & \multicolumn{2}{|c|}{$\lambda=0.1$} \\
\hline & $\begin{array}{c}\text { EWMA } \\
\left(h=2.15351 \times 10^{-10}\right)\end{array}$ & $\begin{array}{c}\text { Modified } \\
\left(b=5.6968 \times 10^{-10}\right)\end{array}$ & $\begin{array}{c}\text { EWMA } \\
\left(h=4.97638 \times 10^{-9}\right)\end{array}$ & $\underset{\left(b=5.00361 \times 10^{-10}\right)}{\text { Modified }}$ \\
\hline 0.00 & 500.018859 & 500.018440 & 500.048462 & 500.049041 \\
\hline 0.001 & 410.684518 & 12.373073 & 418.900893 & 11.525787 \\
\hline 0.003 & 279.691311 & 4.269468 & 296.482942 & 4.020852 \\
\hline 0.005 & 192.837824 & 2.664904 & 212.155442 & 2.537072 \\
\hline 0.01 & 80.144470 & 1.544761 & 96.189807 & 1.501932 \\
\hline 0.05 & 1.406011 & 1.004560 & 1.824931 & 1.004121 \\
\hline 0.10 & 1.007555 & 1.000146 & 1.022682 & 1.000130 \\
\hline 0.30 & 1.000009 & 1.000000 & 1.000051 & 1.000000 \\
\hline 0.50 & 1.000001 & 1.000000 & 1.000005 & 1.000000 \\
\hline 1.00 & 1.000000 & 1.000000 & 1.000000 & 1.000000 \\
\hline 2.00 & 1.000000 & 1.000000 & 1.000000 & 1.000000 \\
\hline$R M I$ & 21.935199 & 0.000000 & 25.458726 & 0.000000 \\
\hline Shift size & \multicolumn{2}{|c|}{$\lambda=\mathbf{0 . 1 5}$} & \multicolumn{2}{|c|}{$\lambda=\mathbf{0 . 2}$} \\
\hline$(\delta)$ & $\begin{array}{c}\text { EWMA } \\
\left(h=8.7735 \times 10^{-6}\right)\end{array}$ & $\begin{array}{c}\text { Modified } \\
\left(b=4.45335 \times 10^{-10}\right)\end{array}$ & $\begin{array}{c}\text { EWMA } \\
\left(h=9.2341 \times 10^{-4}\right)\end{array}$ & $\begin{array}{c}\text { Modified } \\
\left(b=4.009478 \times 10^{-10}\right)\end{array}$ \\
\hline 0.00 & 500.061271 & 500.067195 & 500.027847 & 500.029982 \\
\hline 0.001 & 443.510830 & 10.806701 & 459.400446 & 10.190344 \\
\hline 0.003 & 350.844729 & 3.810433 & 389.296622 & 3.630480 \\
\hline 0.005 & 279.559120 & 2.428984 & 331.547146 & 2.336624 \\
\hline 0.01 & 163.232107 & 1.465789 & 226.523241 & 1.434960 \\
\hline 0.05 & 7.394604 & 1.003757 & 23.667633 & 1.003452 \\
\hline 0.10 & 1.543142 & 1.000116 & 4.865620 & 1.000105 \\
\hline 0.30 & 1.007718 & 1.000000 & 1.171529 & 1.000000 \\
\hline 0.50 & 1.001440 & 1.000000 & 1.048075 & 1.000000 \\
\hline 1.00 & 1.000237 & 1.000000 & 1.011600 & 1.000000 \\
\hline 2.00 & 1.000061 & 1.000000 & 1.003766 & 1.000000 \\
\hline$R M I$ & 36.248876 & 0.000000 & 47.475014 & 0.000000 \\
\hline
\end{tabular}

4 Where $\lambda$ is a smoothing parameter, $b$ is UCL of the modified chart, and $h$ is UCL of the 5 EWMA chart. 
Figure 1

The process detecting of PM2.5 level observations of modified EWMA control chart.

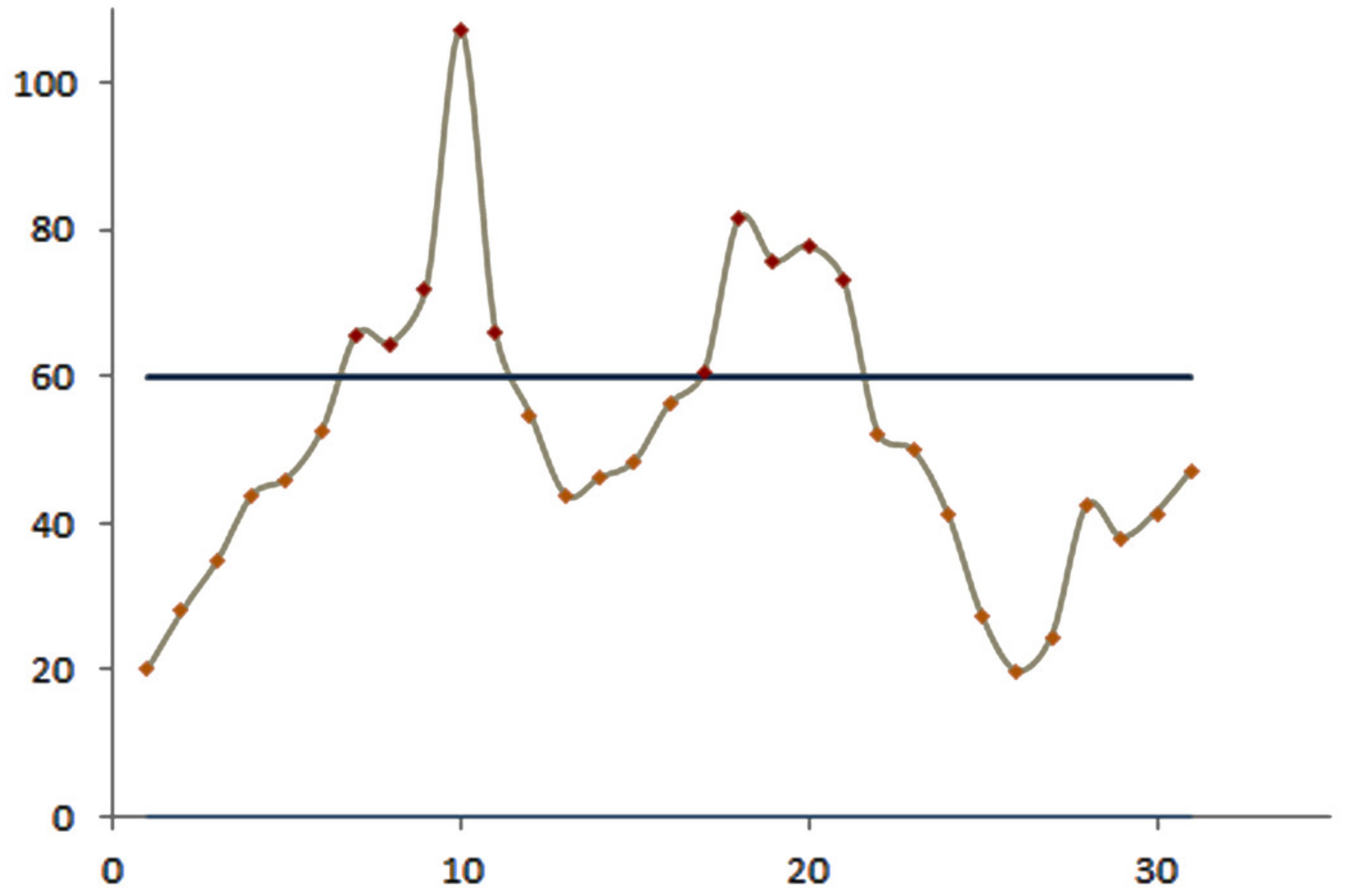


Figure 2

The process detecting of PM2.5 level observations of EWMA control chart.

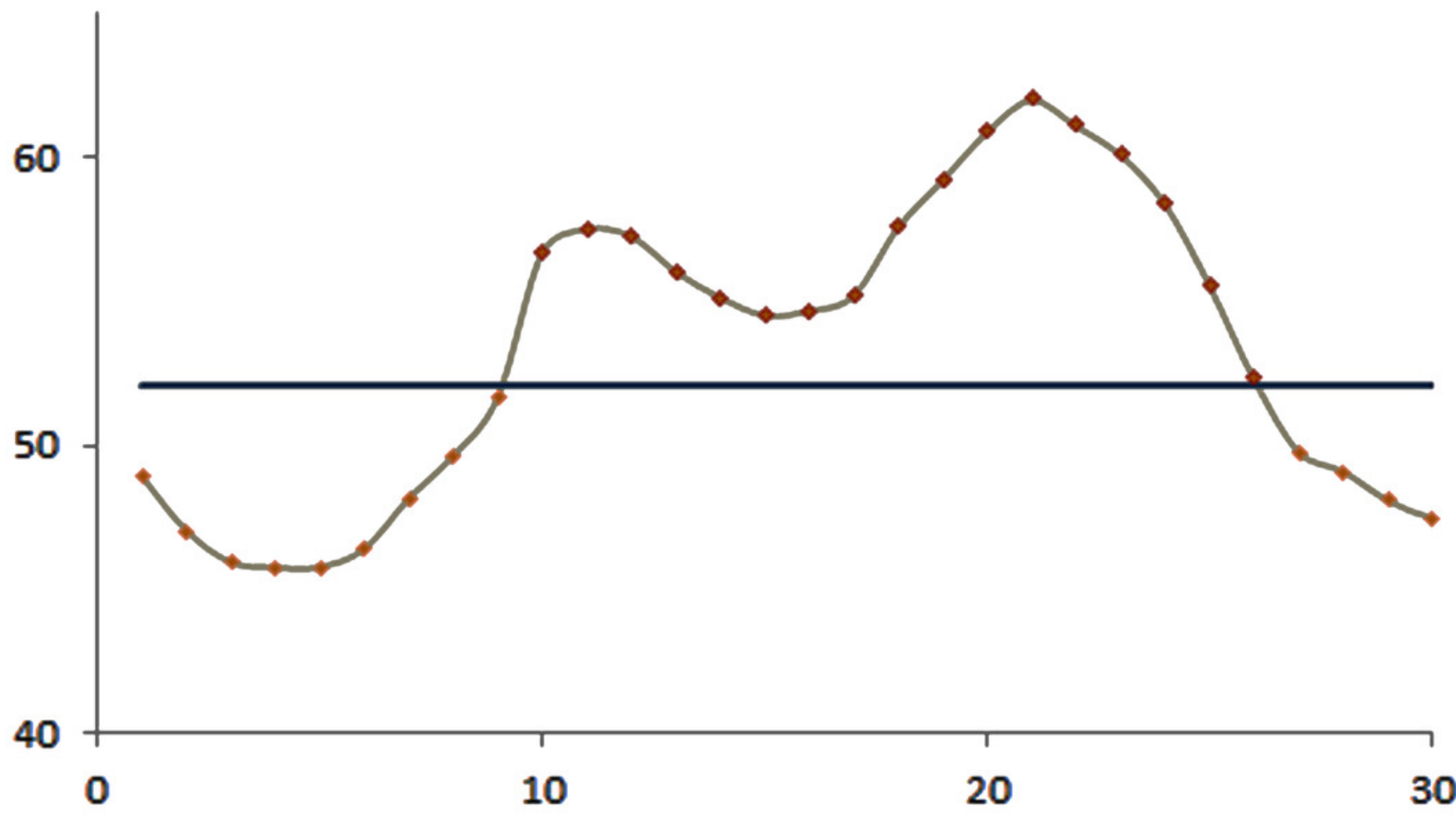


Figure 3

The process detecting of $\mathrm{CO}$ gas level observations of modified EWMA control chart.

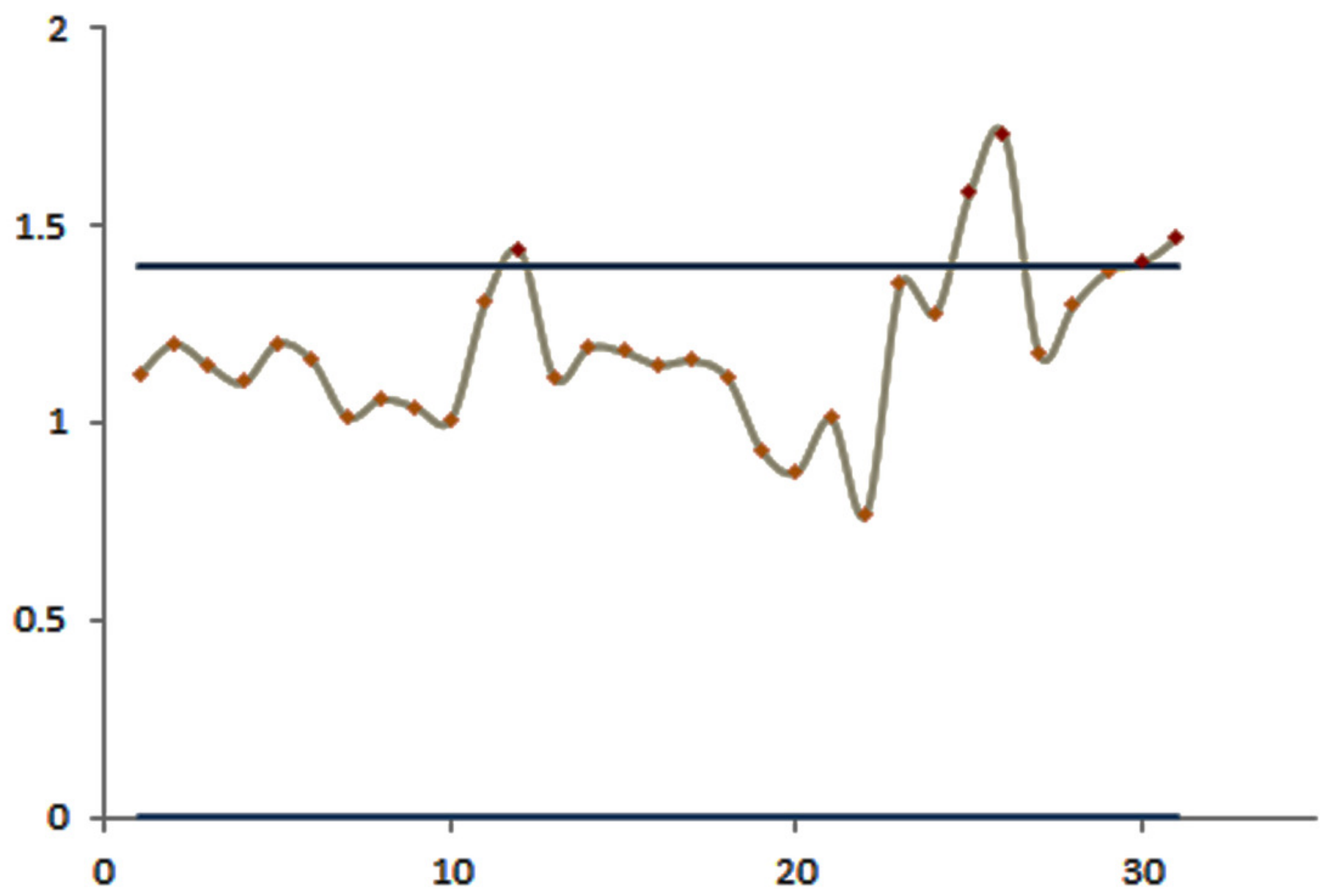


Figure 4

The process detecting of $\mathrm{CO}$ gas level observations of EWMA control chart.

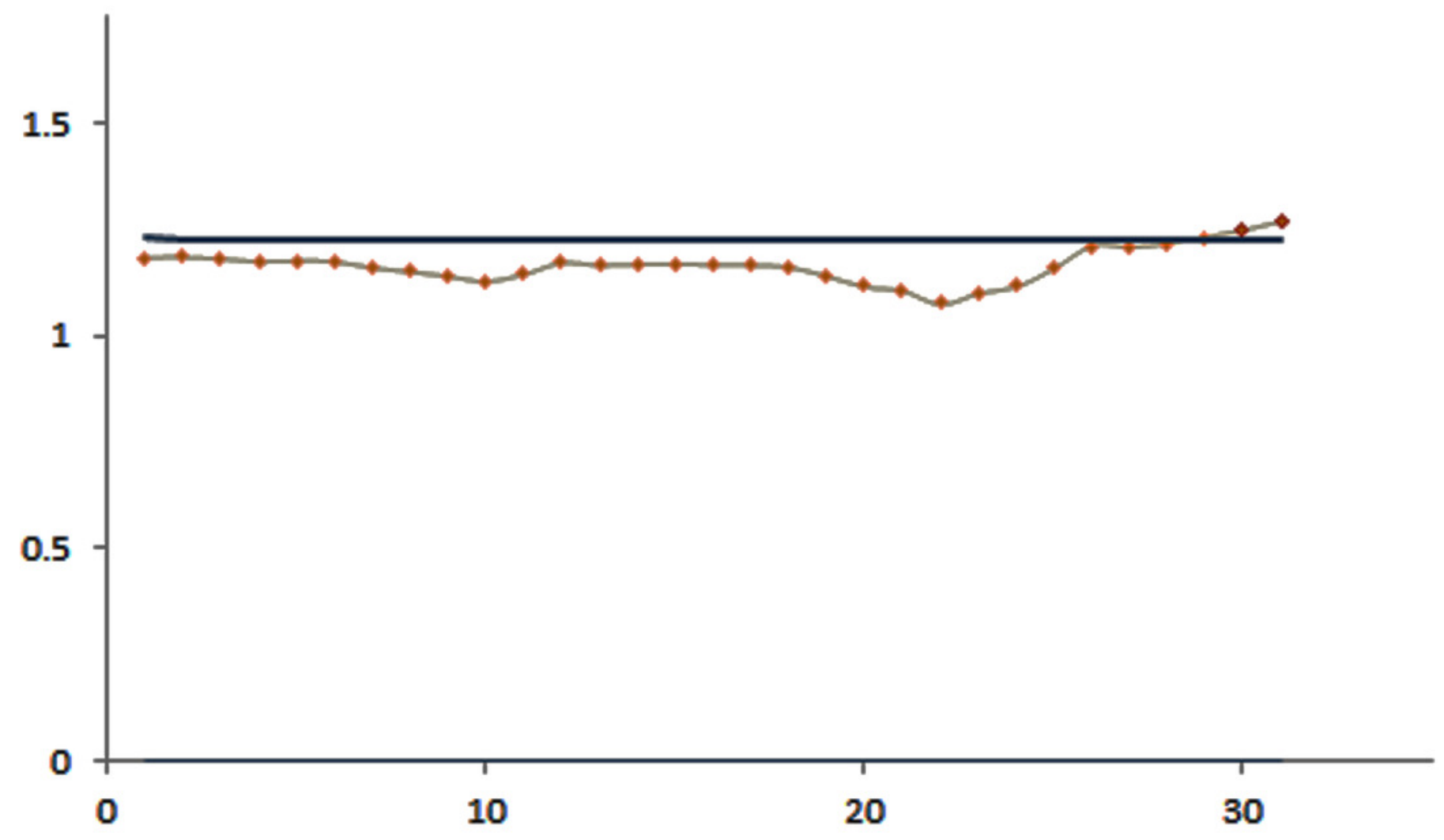

